\title{
An effective UFLC-MS/MS method used to study pharmacokinetics of major constituents of Fukeqianjin formula in rat plasma
}

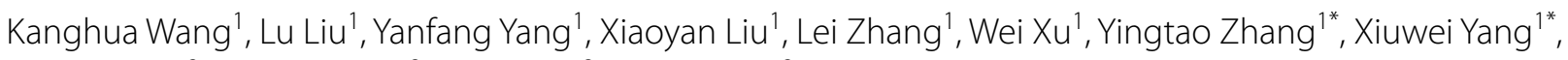
Peng Zhang ${ }^{2}$, Kaifeng Peng ${ }^{2}$, Yun Gong ${ }^{2}$ and Nifu Liu ${ }^{2}$

\begin{abstract}
Background: Fukeqianjin formula (FKQJF) is a Chinese medicine prescription, which has been widely used individually or in combination with other western medicine for the treatment of various gynecological inflammatory diseases, including chronic cervicitis, chronic pelvic inflammatory disease and endometritis, so on and so force.

Methods: The ultra-fast liquid chromatography coupled with triple quadrupole tandem mass spectrometry (UFLCMS/MS), a quick and efficient method was established and applied to quantify the major constituents of Fukegianjin formula in rat plasma, and its pharmacokinetics of oral absorption was studied. Nineteen components in Fukeqianjin formula were detected and identified as the major compounds absorbed into the blood according to their chromatographic behavior, molecular weight, ion fragments and other information of these compounds. Furthermore, the plasma drug concentration-time curves were established and the related kinetic parameters were analyzed.

Results: The results showed that all the 19 compounds could be rapidly absorbed by the gastrointestinal tract, the plasma drug concentration of most compounds could reach a peak at around $1-2 \mathrm{~h}$, and the double-peaks on behalf of the enterohepatic circulation were found in most drug concentration-time curves. The method used in this experiment was validated comprehensively including specificity, linearity, precision, accuracy, stability, matrix effect, and recovery.
\end{abstract}

Conclusions: These results showed that the developed method was suitable for pharmacokinetic analysis of the main components of Fukeqianjin formula in rat plasma, and may provide useful information for the subsequent distribution studies in vivo.

Keywords: Fukeqianjin formula, Pharmacokinetics, UFLC-MS/MS

*Correspondence: zytao@bjmu.edu.cn; xwyang@bjmu.edu.cn

1 State Key Laboratory of Natural and Biomimetic Drugs, Department of Natural Medicines, School of Pharmaceutical Sciences, Peking University Health Science Center, Peking University, No. 38, Xueyuan Road, Haidian District, Beijing 100191, China

Full list of author information is available at the end of the article

\section{Background}

Traditional Chinese medicine (TCM) prescriptions are usually made up of several medicinal herbals according to certain mass ratios guided by traditional Chinese medicine theory, not simply the addition of herbs. It is well known that the multiple constituents contribute to the therapeutic and synergistic effects of traditional Chinese medicine (TCM), and the chemical components absorbed into blood have more possibilities of showing

(c) The Author(s) 2020. This article is licensed under a Creative Commons Attribution 4.0 International License, which permits use, sharing, adaptation, distribution and reproduction in any medium or format, as long as you give appropriate credit to the original author(s) and the source, provide a link to the Creative Commons licence, and indicate if changes were made. The images or other third party material in this article are included in the article's Creative Commons licence, unless indicated otherwise in a credit line to the material. If material is not included in the article's Creative Commons licence and your intended use is not permitted by statutory regulation or exceeds the permitted use, you will need to obtain permission directly from the copyright holder. To view a copy of this licence, visit http://creativeco mmons.org/licenses/by/4.0/. The Creative Commons Public Domain Dedication waiver (http://creativecommons.org/publicdomain/ zero/1.0/) applies to the data made available in this article, unless otherwise stated in a credit line to the data. 
pharmacological activity. Furthermore, the efficacy of TCM does not simply equal the sum of the efficacies of all active components. Therefore, identification of the absorbed chemical components and metabolites are therefore very important for elucidating the therapeutic material basis and action mechanism of TCM.

Fukeqianjin formula (FKQJF), a Chinese medicine prescription, consists of eight Chinese medicinal materials including Moghaniae Radix, Rosae Laevigatae Radix, Andrographis Herba, Mahoniae Caulis, Zanthoxyli Radix et Caulis, Angelicae Sinensis Radix, Spatholobi Caulis, and Codonopsis Radix [1]. FKQJF has been widely used individually or in combination with other western medicine for the treatment of various gynecological inflammatory diseases, including chronic cervicitis, chronic pelvic inflammatory disease, endometritis, etc. [2-4]. Modern pharmacological studies and clinical practices have demonstrated its anti-inflammatory, bacteriostasis, and analgesic effects $[5,6]$. Our previous study on the chemical components of FKQJF showed that it contained numerous diverse compounds, including flavonoids, alkaloids, diterpenes, phenols, phthalides, and phenylpropanoids, etc. [7]. The diterpenes (neoandrographolide, andrographolide, 14-deoxy-11,12-didehydroandrographolide and andrograpanin) and flavonoids (7-O-methylwogonin and skullcapflavone I) are considered to be the main bioactive components of Andrographis Herba; the alkaloids (methyl-5-hydroxy-2-pyridinecarboxylate, acortatarin A, 9-epi-acortatarin A, jatrorrhizine, palmatine, and berberine) and phenol (3,4,5-trimethoxyphenyl-1-O$\beta$-D-glucopyranoside) originated from Mahoniae Caulis, especially jatrorrhizine, palmatine, and berberine are considered to be the primary bioactive compounds of Mahoniae Caulis.; the phthalide (Z-ligustilide) and phenylpropanoid (ferulic acid) are the main effective ingredients isolated from Angelicae Sinensis Radix; the flavonoid (genistin) is the effective ingredient isolated from Moghaniae Radix and the flavonoids (ononin and naringenin) originated from Spatholobi Caulis. These complex ingredients are the main bioactive components of FKQJF and show a variety of pharmacological effects. For example, Liu et al. tested the anti-inflammatory activities of neoandrographolide and andrograpanin, which could significant suppressed the level of NO and TNF- $\alpha$ in LPS-induced inflammatory model $[8,9]$. As for the alkaloids, jatrorrhizine, palmatine, and berberine were reported exhibited various activities, such as antiinflammatory, antinociceptive and anti-pyretic activities $[10,11]$, and being used to help treat several diseases in clinic. Ononin, naringenin and genistin are the mainly flavonoids isolated from FKQJF, which exhibited significant anticancer, anti-inflammatory, and antibacterial activities, especially for the estrogen-like activity and being used for the alleviation of menopause symptoms $[12,13]$. However, there is still no report focused on the in vivo absorbed components of FKQJF. Accordingly, it is necessary to establish a rapid and sensitive analytical method for detection and quantification of the absorbed components of FKQJF.

Ultra-fast liquid chromatographic coupled with electrospray ionization triple quadrupole tandem mass spectrometry (UFLC-MS/MS) technology is suitable for the analysis of the complex system of TCM, especially for the low concentration components. The main purpose of this study is to establish and validate a rapid, accurate, precise, sensitive, and selective UFLC-MS/MS for the identification and quantification of 19 major constituents of FKQJF in rat plasma after oral administration of FKQJF. It was expected that the results of this study could provide helpful information for further understanding the relationship between the chemical constituents and pharmacological activity of FKQJF.

\section{Materials and methods Materials and reagents}

Moghaniae Radix is the dried roots of Moghania macrophylla (Willd.) O. Kuntze and was obtained from Xishuangbanna Dai Autonomous Prefecture of Yunnan province of China. Rosae Laevigatae Radix is the dried roots of Rosa laevigata Michx. and was obtained from Yongshun county of Hunan province of China. Andrographis Herba is the dried aerial parts of Andrographis paniculata (Burm. f.) Nees and was gathered from Suixi county of Zhanjiang city in Guangdong province of China. Mahoniae Caulis is the dried stems of Mahonia bealei (Fort.) Carr. and was purchased from Yunnan province of China. Zanthoxyli Caulis is the dried stems of Zanthoxylum dissitum Hemsl. and was purchased from Yanling county of Zhuzhou city in Hunan province of China. Angelicae Sinensis Radix is the dried roots of Angelica sinensis (Oliv.) Diels and Codonopsis Radix is the dried roots of Codonopsis pilosula (Franch.) Nannf., both were purchased from Longxi county of Gansu province of China. And Spatholobi Caulis is the dried vine stem of Spatholobus suberectus Dunn and was harvested from Pu'er city, Yunnan province of China. All the crude drugs were identified by Prof. Xiu-Wei Yang at the School of Pharmaceutical Sciences, Peking University Health Science Center, Peking University. Voucher specimens were deposited at the herbarium of Zhuzhou Qianjin Pharmaceutical Co., Ltd. (Hunan, China) and school of Pharmaceutical Sciences, Peking University (Beijing, China).

Reference compounds including 3,4,5-trimethoxyphenol1-O- $\beta$-D-glucopyranoside (1), 5-hydroxypicolinic acid methyl ester (2), acortatarin A (3), 9-epi-acortatarin A 
(4) were isolated from Mahoniae Caulis [14], neoandrographolide (5), trans-ferulic acid (6), genistin (7), salicylic acid (8), jatrorrhizine (9), palmatine (11), andrographolide (12), berberine (13), 14-deoxy-11,12-didehydro-andrographolide (15), panicolin (16), andrograpanin (17), Z-ligustilide (18), and 7-O-methylwogonin (19) were isolated from the extracts of Fukeqianjin Formula as described in our previous report [7], ononin (10) and naringenin (14) were isolated from Spatholobi Caulis [15]. The internal standard (I.S.) bavachin was isolated from the mature fruits of Psoralea corylifolia L. [16]. Their purity was determined to be above $98 \%$ by LC-MS and the chemical structures are shown in Fig. 1.

Heparin sodium injection (Lot\# 20150602) was purchased from Tianjin Biochemical Pharmaceutical Co., Ltd. (Tianjin, China). Methanol $(\mathrm{MeOH})$, acetonitrile $(\mathrm{ACN})$ and formic acid of LC-MS grade were provided by Fisher Scientific Inc. (Pittsburgh, PA, USA). Deionized water $(18.2 \mathrm{M} \Omega \mathrm{cm})$ was purified by Millipore Alpha$\mathrm{Q}$ water purification system (Millipore, Bedford, MA, USA).

\section{Animals}

Rat experiment was carried out based on following the guideline of the Care and Use of Laboratory Animals in Beijing that was approved by Animal Care and Use Committee of Peking University (Approval No. LA 2018143, 1 March 2018). Male Sprague-Dawley (SD) rats with the weight of $220 \pm 20 \mathrm{~g}$, were provided by Laboratory animal center of Peking University Health Science Center. These rats were raised in a standard environment with temperature of $24 \pm 2{ }^{\circ} \mathrm{C}$, relative humidity of $60 \pm 5 \%$, and LD 12:12 cycles. They could acclimatize the environment for a week before the experiment, free drinking water and conventional feed were normally supplied during this period.

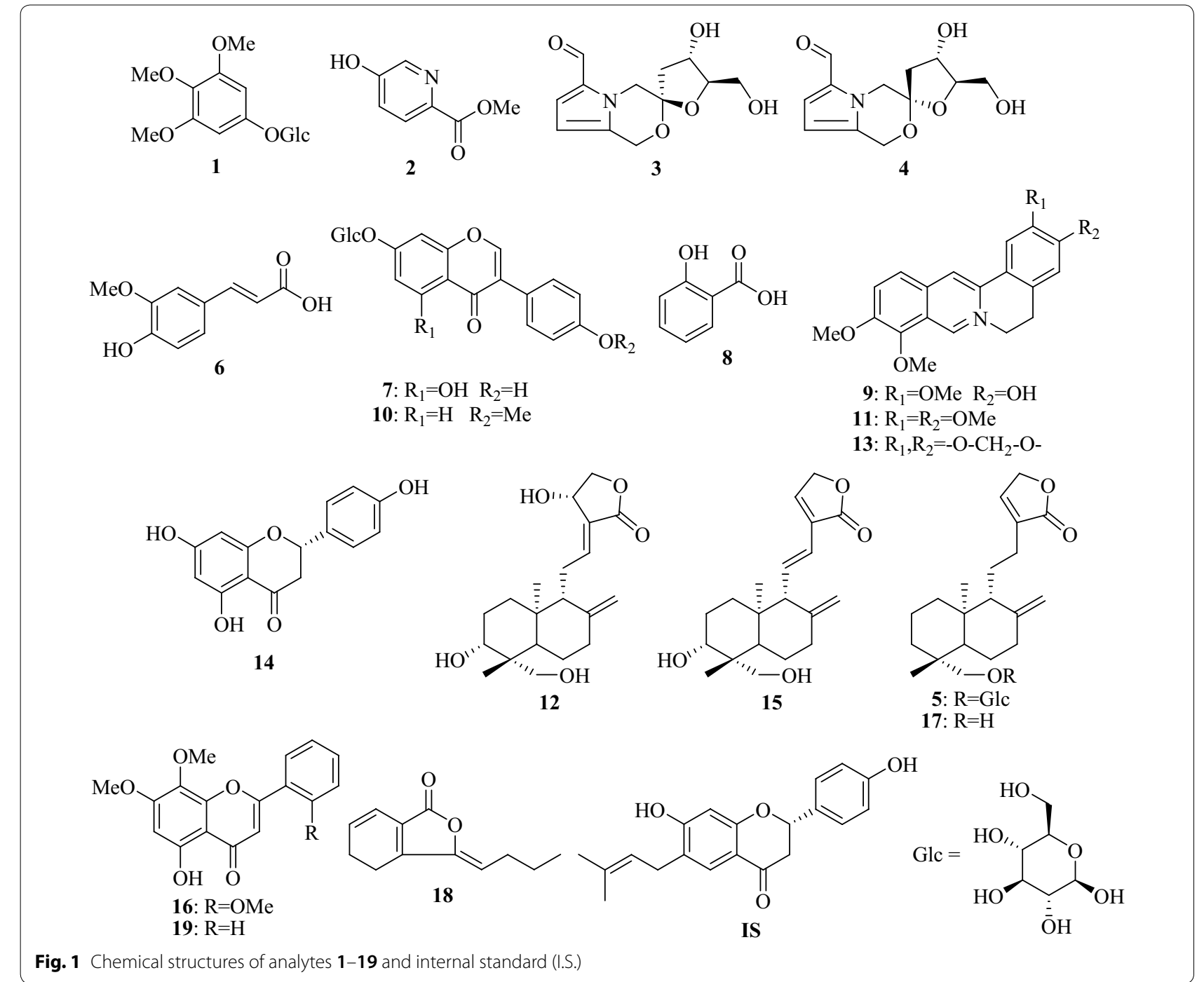




\section{Preparation of FKQJF extract}

FKQJF extract was prepared and freeze-dried by using standard method as described previously [1] and obtained from Zhuzhou Qianjin pharmaceutical Co., Ltd. Chiefly, $21 \mathrm{~g}$ dried FKQJF extract was added into moderate amount of distilled water to dissolved completely by ultrasonic treatment, then diluted to get a suspension of $0.42 \mathrm{~g} / \mathrm{mL}$.

\section{Pretreatment of plasma samples}

Aliquots of $100 \mu \mathrm{L}$ plasma samples were mixed with $10 \mu \mathrm{L}$ I.S. samples $(1 \mu \mathrm{g} / \mathrm{mL}$, in $\mathrm{MeOH})$, then added with $500 \mu \mathrm{L} \mathrm{ACN}$, respectively, and vortexed for $5 \mathrm{~min}$, centrifugated at 10,000 rpm for $10 \mathrm{~min}$, the supernatants were transferred into clean vials and dried in a vacuum centrifugal concentrator at $1200 \mathrm{rpm}, 37^{\circ} \mathrm{C}$. After that, $100 \mu \mathrm{L}$ ACN was added and ultrasonic (frequency $40 \mathrm{kHz}$, power $250 \mathrm{~W}$ ) extracted for $5 \mathrm{~min}$ to dissolve the dry residue, vortexed for $1 \mathrm{~min}$ and centrifugated at $10,000 \mathrm{rpm}$ for $5 \mathrm{~min}, 1 \mu \mathrm{L}$ of each final supernatant was injected into UFLC-MS/MS for analysis.

\section{Instrument and analytical conditions}

An 8050 UFLC-MS/MS system equipped with LC-30A binary pump, a SIL-30AC autosampler, a SPD-M30A
PDA detector, a CTO-20AC column oven, and a 8050 triple quadrupole mass spectrometer with an electrospray ionization source (ESI) was applied to detect and quantify FKQJF compounds in plasma samples. Data were acquired and processed with the software LabSolution (Ver. 5.6).

A Kinetex XB-C $\mathrm{C}_{18}$ HPLC column $(100 \times 2.1 \mathrm{~mm}$, $2.6 \mu \mathrm{m}$ ) linked with an equivalent guard column was used for chromatographic separation. The aqueous phase contained $0.2 \%$ formic acid was used as mobile phase $\mathrm{A}$, and organic phase ACN as mobile phase B. The gradient elution method using in this program was: $3-5 \mathrm{~min}, 28-31 \%$ B; 5-7 min, 31-34\% B; 7-9 min, 34-65\% B; 9-10 min, $65-95 \% \mathrm{~B} ; 10-11.5 \mathrm{~min}, 95 \% \mathrm{~B}$. The flow rate of mobile phase, column temperature and autosampler temperature was $0.4 \mathrm{~mL} / \mathrm{min}, 30{ }^{\circ} \mathrm{C}$ and $4{ }^{\circ} \mathrm{C}$, respectively. The injection volume of each sample was set as $1 \mu \mathrm{L}$. The main MS spectrum parameters were set as follows: the flow rate of drying gas $\left(\mathrm{N}_{2}\right)$ was $10.0 \mathrm{~L} / \mathrm{min}$; the atomized gas was $3.0 \mathrm{~L} / \mathrm{min}$ and the heating gas flow rate was $10.0 \mathrm{~L} / \mathrm{min}$. The main temperatures of interface, desolvation and heat block was $300{ }^{\circ} \mathrm{C}, 250{ }^{\circ} \mathrm{C}$ and $400{ }^{\circ} \mathrm{C}$, respectively. And, the interface and detector voltage were $3 \mathrm{kV}$ and $1.8 \mathrm{kV}$. The specific parameter values corresponding to each compound were shown in Table 1.

Table 1 The information of compound ionization

\begin{tabular}{|c|c|c|c|c|c|c|c|}
\hline \multirow[t]{2}{*}{ Analyte } & \multirow{2}{*}{$\begin{array}{l}\text { Retention time } \\
\text { (min) }\end{array}$} & \multicolumn{2}{|c|}{ MRM transition $(m / z)$} & \multirow{2}{*}{$\begin{array}{l}\text { Dwell time } \\
\text { (msec) }\end{array}$} & \multirow[t]{2}{*}{$\mathrm{Q}_{1}$ pre bias $(\mathrm{V})$} & \multirow{2}{*}{$\begin{array}{l}\text { Collision } \\
\text { energy (V) }\end{array}$} & \multirow[t]{2}{*}{$\mathrm{Q}_{3}$ pre bias $(\mathrm{V})$} \\
\hline & & Precursor ion & Product ion & & & & \\
\hline 1 & 2.022 & 347.05 & 185.10 & 22 & -21 & -13 & -18 \\
\hline 2 & 2.079 & 154.20 & 94.00 & 22 & -25 & -10 & -26 \\
\hline 3 & 2.184 & 254.15 & 206.05 & 22 & -15 & -10 & -25 \\
\hline 4 & 2.464 & 254.20 & 206.05 & 22 & -15 & -10 & -21 \\
\hline 5 & 2.539 & 481.2 & 23.05 & 22 & -26 & -45 & -29 \\
\hline 6 & 3.206 & 195.05 & 89.00 & 22 & -25 & -33 & -16 \\
\hline 7 & 3.571 & 431.10 & 268.05 & 22 & 16 & 30 & 28 \\
\hline 8 & 3.835 & 137.10 & 93.05 & 22 & 10 & 16 & 29 \\
\hline 9 & 3.837 & 338.20 & 323.10 & 22 & -25 & -24 & -15 \\
\hline 10 & 3.979 & 431.10 & 269.10 & 22 & -24 & -22 & -28 \\
\hline 11 & 4.324 & 352.20 & 336.10 & 22 & -19 & -31 & -16 \\
\hline 12 & 4.355 & 395.25 & 331.10 & 22 & 28 & 12 & 22 \\
\hline 13 & 4.461 & 336.15 & 320.15 & 22 & -24 & -31 & -15 \\
\hline 14 & 5.701 & 273.10 & 153.00 & 22 & -30 & -22 & -15 \\
\hline 15 & 7.354 & 333.2 & 292.05 & 31 & -19 & -10 & -30 \\
\hline 16 & 8.928 & 315.10 & 300.05 & 46 & -26 & -22 & -20 \\
\hline 17 & 9.391 & 319.25 & 301.15 & 46 & -30 & -13 & -20 \\
\hline 18 & 9.670 & 191.10 & 77.05 & 46 & -13 & -41 & -29 \\
\hline 19 & 9.715 & 299.10 & 283.00 & 46 & -30 & -32 & -19 \\
\hline I.S. & 9.186 & 325.15 & 149.00 & 46 & -30 & -35 & -20 \\
\hline
\end{tabular}

Dwell time: residence time during an acquisition point; Q1 pre bias: voltage promotes the ionization of the precursor ion; Q3 pre bias: voltage promotes the ionization of the product ion 


\section{Method validation}

The analysis method established in this experiment was systematically examined for specificity, linear, precision, accuracy, stability, recovery and matrix effect in accordance with guidelines for the validation of quantitative analytical methods for biological samples in Guidance for Industry: Bioanalytical Method Validation [17].

\section{Method specificity}

The specificity of UFLC-MS/MS method was verified by analyzing and comparing the chromatograms generated by the following three groups: Six pure blank plasma samples added with $100 \mu \mathrm{L}$ ACN; Six blank plasma samples added with $100 \mu \mathrm{L}$ ACN containing mixed reference compounds and I.S.; Six plasma samples collected from FKQJF-administrated rats and prepared as described in the section of "Pretreatment of plasma samples".

\section{Linearity, and lower limits of detection and quantification}

The standard curve of each compound was established by weighted least squares method (WLS) drawing the peak area ratios of compound/I.S. $(y)$ versus the corresponding concentrations of each compound $(x)$. Each of these compounds was diluted into a series of concentrations in $\mathrm{MeOH}$, followed by twofold dilution enable to cover all the range of plasma drug concentrations. The initial concentration of each compound in linear range was: $625 \mathrm{ng} /$ $\mathrm{mL}$ for $\mathbf{1}, \mathbf{2}, \mathbf{3}, \mathbf{4}, \mathbf{5}, \mathbf{8}, \mathbf{1 0}$ and 14; $743.75 \mathrm{ng} / \mathrm{mL}$ for $\mathbf{6}$; $656.25 \mathrm{ng} / \mathrm{mL}$ for $7 ; 200 \mathrm{ng} / \mathrm{mL}$ for $9 ; 303.13 \mathrm{ng} / \mathrm{mL}$ for 11; $768.75 \mathrm{ng} / \mathrm{mL}$ for $12 ; 350 \mathrm{ng} / \mathrm{mL}$ for $13 ; 312.5 \mathrm{ng} /$ $\mathrm{mL}$ for $15 ; 637.5 \mathrm{ng} / \mathrm{mL}$ for $16 ; 768.75 \mathrm{ng} / \mathrm{mL}$ for 17 ; $518.75 \mathrm{ng} / \mathrm{mL}$ for $\mathbf{1 8} ; 450 \mathrm{ng} / \mathrm{mL}$ for 19 . The lower limit of detection (LLOD) and lower limit of quantification (LLOQ) were calculated according to the signal-to-noise ratio $(S / N)$ of 3 and 10 , respectively.

\section{Precision and accuracy}

The precision of intra-day and inter-day was obtained by calculating low, medium and high plasma concentrations of reference compounds in blank plasma. First, the low, medium and high concentrations of reference compounds was added in each blank plasma sample, six samples were prepared in parallel at each concentration and processed according to the section of "Pretreatment of plasma samples". The intra-day and inter-day precision were investigated by repeating this experiment six times in 1 day, and repeating once for 3 days, respectively. The accuracy was evaluated by calculating the consistency of the measured concentration with the initial concentration.

\section{Stability}

Six replicates of low, medium and high concentrations of quality control (QC) samples were used to verify the stabilities under different conditions including: place at room temperature for $8 \mathrm{~h}$, freeze $\left(-20^{\circ} \mathrm{C}\right)$ and thaw for three times, and store at $-20^{\circ} \mathrm{C}$ for 20 days.

\section{Recovery and matrix effect}

For recovery test, the blank plasma sample $(100 \mu \mathrm{L})$ was mixed with $100 \mu \mathrm{L}$ ACN containing low, medium or high concentration of the reference compounds and I.S., extracted with $500 \mu \mathrm{L}$ ACN and further processed as described in the section of "Pretreatment of plasma samples", and the peak area of each compound was labeled as A. For recovery control and matrix effect test, the blank plasma sample was replaced with $100 \mu \mathrm{L}$ ACN containing the same three concentrations of the reference compounds and the peak area of each analyte was signed as B. For matrix effect control, the blank plasma sample was first extracted with $500 \mu \mathrm{L}$ ACN to remove the precipitate, then mixed with $100 \mu \mathrm{L} \mathrm{ACN}$ containing same concentration of the reference compounds and I.S. as above and processed, and the peak area was labeled as $C$. The ratios of $A$ to $B$ and $C$ to $B$ were adopted for calculating recovery and matrix effect, respectively.

\section{Pharmacokinetic study}

Rats were divided into a blank group and a FKQJF administration group (6 rats for each), and fasted for $24 \mathrm{~h}$. Each rat of the administration group was given FKQJF extract suspension at a single dose of $3.2 \mathrm{~g} F K Q J F / \mathrm{kg}$ body weight through oral administration in parallel. Blood samples $(0.25 \mathrm{~mL})$ were gathered from the orbital venous plexus of each rat, with FKQJF group gathered at 14 serial timepoints (6 rats for each) as $0.083 \mathrm{~h}, 0.16 \mathrm{~h}, 0.33 \mathrm{~h}$, 0.5 h, 0.75 h, 1.0 h, 1.5 h, 2 h, 3 h, 4 h, 6 h, 8 h, 12 h and $24 \mathrm{~h}$ after drug administration. The blood samples were centrifugated at $6000 \mathrm{~g}$ for $10 \mathrm{~min}$ to isolate plasma and stored at $-20{ }^{\circ} \mathrm{C}$ for further analysis.

\section{Data analysis}

Data were analyzed using the Drug and Statistics (DAS) Software version 2.0 (DAS 2.0, Mathematical Pharmacology Professional Committee of China, Shanghai, China). The non-compartmental mode was applied to obtain the following PK parameters: area under the plasma concentration-time curve from time zero to the time of last quantifiable concentration $\left(\mathrm{AUC}_{0 \rightarrow \mathrm{t}}\right)$ and area under the plasma concentration-time curve to time infinity (AUC $0 \rightarrow \infty)$, the elimination half-life $\left(t_{1 / 2}\right)$, mean retention time to last sampling time $\left(\mathrm{MRT}_{0 \rightarrow \mathrm{t}}\right)$ and mean retention time to infinity $\left(\mathrm{MRT}_{0 \rightarrow \infty}\right)$. The maximum plasma concentration $\left(\mathrm{C}_{\max }\right)$ and the time to maximum concentration 

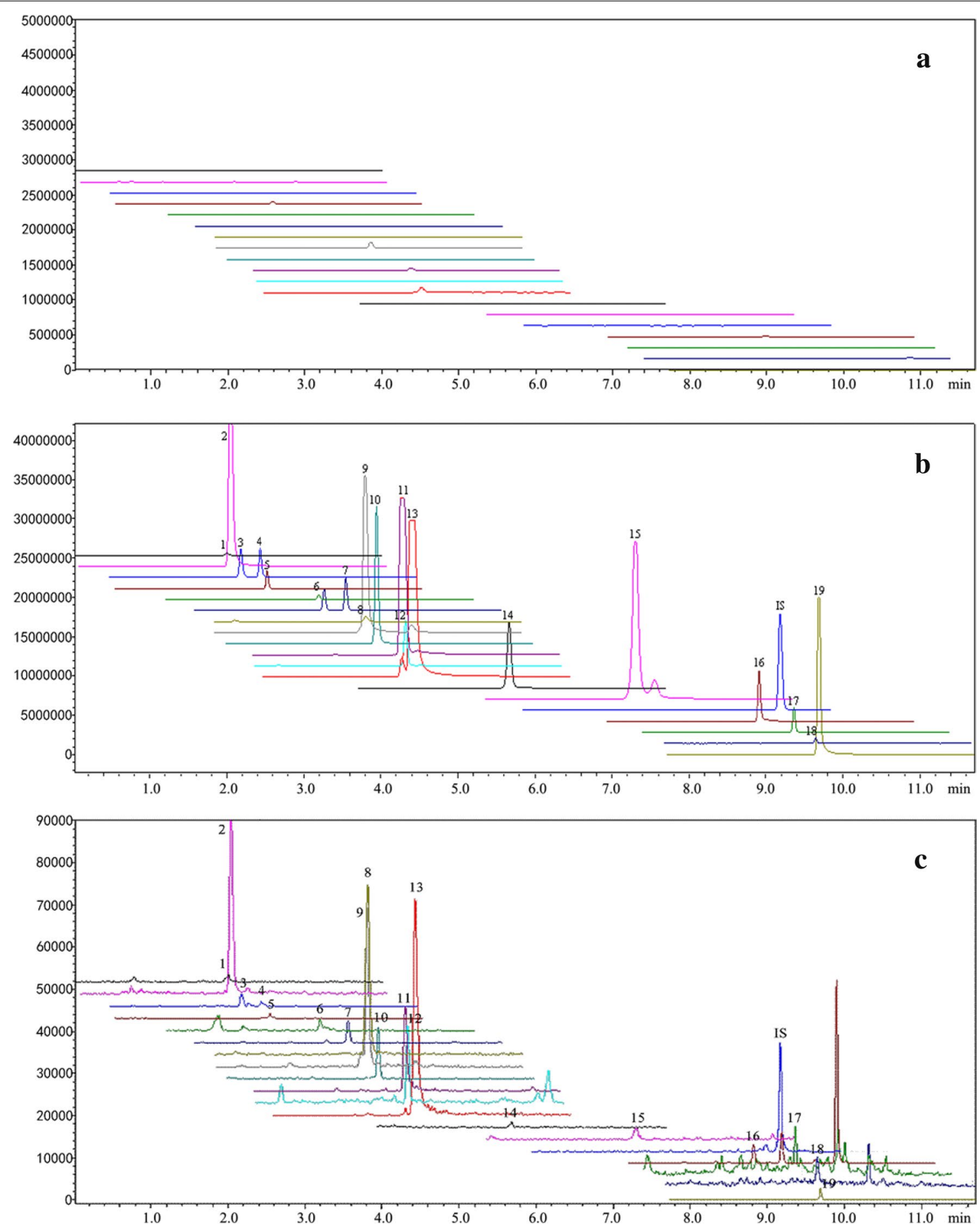

Fig. 2 Typical MRM chromatograms of compounds 1-19 in FKQJF. a The blank plasma sample; $\mathbf{b}$ Blank plasma sample added with the reference compounds and I.S., c Plasma sample collected from rats after oral administration

$\left(\mathrm{T}_{\max }\right)$ were observed directly from the concentrationtime $(\mathrm{C}-\mathrm{T})$ curves and measured data. All data are presented as mean $\pm \mathrm{SD}$.
Results

Method validation

Specificity

When comparing the chromatograms of blank plasma samples, blank plasma samples added with the reference 
Table 2 The linear regression equation, linear range, LLOQ and LLOD of 19 compounds in FKQJF

\begin{tabular}{llllll}
\hline Analyte & Calibration curve & $\mathbf{r}^{\mathbf{2}}$ & Linear range $\mathbf{n g} / \mathbf{m L})$ & LLOD $(\mathbf{n g} / \mathbf{m L})$ & $\mathbf{L L O Q}(\mathbf{n g} / \mathbf{m L})$ \\
\hline $\mathbf{1}$ & $y=0.0021 x+0.015$ & 0.9993 & $4.88-625$ & 0.73 & 2.12 \\
$\mathbf{2}$ & $y=0.0906 x+1.9797$ & 0.9923 & $4.88-625$ & 0.85 & 2.08 \\
$\mathbf{3}$ & $y=0.0075 x+0.1078$ & 0.9941 & $4.88-625$ & 0.78 & 1.97 \\
$\mathbf{4}$ & $y=0.0053 x+0.062$ & 0.9964 & $4.88-625$ & 1.25 & 2.96 \\
$\mathbf{5}$ & $y=0.0012 x+0.018$ & 0.9956 & $4.88-625$ & 0.68 & 2.45 \\
$\mathbf{6}$ & $y=0.0009 x+0.0019$ & 0.9991 & $5.81-743.75$ & 1.24 & 2.32 \\
$\mathbf{7}$ & $y=0.0035 x+0.0124$ & 0.9910 & $5.13-656.25$ & 1.12 & 2.53 \\
$\mathbf{8}$ & $y=0.0003 x+0.0416$ & 0.9940 & $4.88-625$ & 0.23 & 0.76 \\
$\mathbf{9}$ & $y=0.0816 x+0.6041$ & 0.9936 & $1.56-200$ & 0.76 & 2.36 \\
$\mathbf{1 0}$ & $y=0.0108 x+0.2454$ & 0.9926 & $4.88-625$ & 0.81 & 1.58 \\
$\mathbf{1 1}$ & $y=0.1335 x+0.6769$ & 0.9957 & $2.37-303.13$ & 1.02 & 2.98 \\
$\mathbf{1 2}$ & $y=0.0007 x+0.015$ & 0.9932 & $6.01-768.75$ & 0.88 & 1.75 \\
$\mathbf{1 3}$ & $y=0.1113 x+0.6035$ & 0.9980 & $2.73-350$ & 0.59 & 2.06 \\
$\mathbf{1 4}$ & $y=0.0052 x-0.0095$ & 0.9994 & $4.88-625$ & 0.92 & 2.43 \\
$\mathbf{1 5}$ & $y=0.076 x+0.8723$ & 0.9954 & $4.88-312.5$ & 0.88 & 2.43 \\
$\mathbf{1 6}$ & $y=0.006 x+0.0716$ & 0.9925 & $4.98-637.5$ & 1.04 & 3.32 \\
$\mathbf{1 7}$ & $y=0.0058 x+0.0282$ & 0.9984 & $6.01-768.75$ & 0.93 & 2.33 \\
$\mathbf{1 8}$ & $y=0.0001 x+0.0209$ & 0.9964 & $4.05-518.75$ & 0.34 & 1.05 \\
$\mathbf{1 9}$ & $y=0.0113 x+0.0195$ & 0.9983 & $3.52-450$ & & \\
\hline & & & &
\end{tabular}

compounds containing I.S., and plasma samples after oral administration of FKQJF, we could see that all of the 19 quantifiable compounds including I.S. can be specifically detected. No endogenous substance interference was observed in rat plasma samples at the corresponding retention time of any analyte. The typical MRM chromatograms were shown in Fig. 2.

\section{Linearity, LLOD and LLOQ}

The established analytical method in this experiment was used to detect a series of reference compounds at different concentrations, and the linearities were obtained. The linear regression equation, correlation coefficient $\left(r^{2}\right)$, linear range, LLOQ and LLOD were listed in Table 2. The $r^{2}$ values were between 0.9910 and 0.9994 demonstrated good linearity of regression equation of each compound. Both LLOQ and LLOD were lower than the minimum value of the linear range, indicating that the established method was suitable for quantification of FKQJF compounds absorbed into the blood.

\section{Precision and accuracy}

The data of precision and accuracy were shown in Table 3. The maximum RSD values of the intra-day and inter-day precision of 19 analytes in FKQJF were 14.94\% and $14.81 \%$, respectively, indicating that the errors were within the acceptable criteria (less than 15\%).
Meanwhile, the intra-day accuracy ranged between 80.33 and $119.76 \%$ and the inter-day accuracy ranged between 80.03 and $119.43 \%$. These results show that the method was feasible for this experiment.

\section{Stability}

The stability RSD values of plasma samples and reference compounds containing I.S. were all less than $15 \%$ after being placed at room temperature for $8 \mathrm{~h}$, freezethawed 3 times, or stored at low temperature of $-20{ }^{\circ} \mathrm{C}$ for 20 days. Data shown in Table 4 presented good stability in the process of sample preparation and storation.

\section{Recovery and matrix effect}

As shown in Table 5, the extraction recovery and matrix effect of the analytes with different concentrations ranged from 80.71 to $119.90 \%$ and from 80.43 to $119.79 \%$, respectively, indicating an acceptable recovery and an analysis method without obvious matrix effect.

\section{Pharmacokinetic study}

Plasma samples were prepared according to the method in section of "Pretreatment of plasma samples" and analyzed by using the established method. The blood concentration-time curves of the compounds were shown in Fig. 3, and the pharmacokinetic (PK) parameters were shown in Table 6. 
Table 3 The precision and accuracy of 19 compounds in FKQJF

\begin{tabular}{|c|c|c|c|c|c|}
\hline \multirow[t]{2}{*}{ Analyte } & \multirow[t]{2}{*}{ Spiked (ng/mL) } & \multicolumn{2}{|l|}{ Intra-day } & \multicolumn{2}{|l|}{ Inter-day } \\
\hline & & Precision (RSD \%) & Accuracy (\%) & Precision (RSD \%) & Accuracy (\%) \\
\hline \multirow[t]{3}{*}{1} & 500 & 14.94 & 93.93 & 12.08 & 82.52 \\
\hline & 250 & 6.65 & 108.26 & 6.22 & 91.24 \\
\hline & 50 & 13.39 & 113.94 & 8.75 & 85.02 \\
\hline \multirow[t]{3}{*}{2} & 500 & 12.48 & 112.91 & 13.95 & 80.94 \\
\hline & 250 & 8.48 & 80.88 & 13.18 & 93.34 \\
\hline & 50 & 6.27 & 96.72 & 5.90 & 90.32 \\
\hline \multirow[t]{3}{*}{3} & 500 & 10.61 & 108.40 & 6.47 & 89.09 \\
\hline & 250 & 14.24 & 100.18 & 13.93 & 99.35 \\
\hline & 50 & 8.71 & 82.38 & 4.33 & 97.38 \\
\hline \multirow[t]{3}{*}{4} & 500 & 4.84 & 112.84 & 8.43 & 97.25 \\
\hline & 250 & 5.27 & 100.10 & 6.41 & 119.43 \\
\hline & 50 & 9.46 & 87.00 & 8.11 & 88.31 \\
\hline \multirow[t]{3}{*}{5} & 600 & 7.81 & 108.38 & 8.47 & 112.68 \\
\hline & 300 & 14.76 & 86.11 & 9.76 & 105.33 \\
\hline & 60 & 11.11 & 110.49 & 14.19 & 103.58 \\
\hline \multirow[t]{3}{*}{6} & 600 & 10.81 & 114.84 & 9.43 & 94.40 \\
\hline & 300 & 7.90 & 83.02 & 13.57 & 106.38 \\
\hline & 60 & 10.82 & 108.04 & 8.61 & 90.00 \\
\hline \multirow[t]{3}{*}{7} & 500 & 13.68 & 92.90 & 4.31 & 98.35 \\
\hline & 250 & 12.95 & 81.97 & 10.88 & 98.16 \\
\hline & 50 & 5.48 & 96.41 & 5.00 & 101.20 \\
\hline \multirow[t]{3}{*}{8} & 500 & 8.68 & 92.52 & 14.81 & 104.02 \\
\hline & 250 & 8.61 & 85.92 & 5.69 & 106.35 \\
\hline & 50 & 10.67 & 117.97 & 8.19 & 99.10 \\
\hline \multirow[t]{3}{*}{9} & 150 & 9.92 & 109.50 & 6.29 & 111.14 \\
\hline & 75 & 13.28 & 89.18 & 6.03 & 84.78 \\
\hline & 25 & 10.13 & 87.51 & 5.53 & 80.03 \\
\hline \multirow[t]{3}{*}{10} & 500 & 4.92 & 103.61 & 13.94 & 107.44 \\
\hline & 250 & 10.71 & 91.96 & 9.03 & 98.62 \\
\hline & 50 & 13.94 & 102.51 & 5.47 & 81.71 \\
\hline \multirow[t]{3}{*}{11} & 200 & 8.87 & 86.93 & 11.32 & 89.26 \\
\hline & 100 & 6.63 & 118.80 & 7.25 & 93.71 \\
\hline & 5 & 6.64 & 107.27 & 4.85 & 96.59 \\
\hline \multirow[t]{3}{*}{12} & 600 & 7.59 & 113.80 & 12.96 & 105.22 \\
\hline & 300 & 7.40 & 103.81 & 12.45 & 110.32 \\
\hline & 60 & 7.82 & 118.22 & 11.99 & 109.08 \\
\hline \multirow[t]{3}{*}{13} & 200 & 9.81 & 89.49 & 7.92 & 89.26 \\
\hline & 100 & 4.34 & 108.30 & 4.10 & 99.07 \\
\hline & 5 & 8.16 & 92.97 & 13.95 & 108.55 \\
\hline \multirow[t]{3}{*}{14} & 500 & 5.45 & 86.37 & 6.65 & 93.67 \\
\hline & 250 & 10.77 & 119.76 & 14.21 & 83.17 \\
\hline & 50 & 4.49 & 83.50 & 9.89 & 119.30 \\
\hline \multirow[t]{3}{*}{15} & 600 & 13.10 & 112.68 & 8.06 & 110.97 \\
\hline & 300 & 6.90 & 91.02 & 10.91 & 88.92 \\
\hline & 60 & 13.93 & 103.81 & 9.02 & 92.39 \\
\hline \multirow[t]{3}{*}{16} & 500 & 5.70 & 85.56 & 13.38 & 87.62 \\
\hline & 250 & 11.61 & 89.73 & 14.78 & 100.02 \\
\hline & 50 & 9.72 & 118.83 & 10.08 & 96.61 \\
\hline
\end{tabular}


Table 3 (continued)

\begin{tabular}{|c|c|c|c|c|c|}
\hline \multirow[t]{2}{*}{ Analyte } & \multirow[t]{2}{*}{ Spiked (ng/mL) } & \multicolumn{2}{|l|}{ Intra-day } & \multicolumn{2}{|l|}{ Inter-day } \\
\hline & & Precision (RSD \%) & Accuracy (\%) & Precision (RSD \%) & Accuracy (\%) \\
\hline \multirow[t]{3}{*}{17} & 600 & 8.29 & 109.97 & 7.57 & 95.28 \\
\hline & 300 & 4.62 & 102.48 & 4.25 & 93.29 \\
\hline & 60 & 14.85 & 90.07 & 4.57 & 99.00 \\
\hline \multirow[t]{3}{*}{18} & 400 & 4.68 & 100.57 & 12.66 & 109.09 \\
\hline & 200 & 10.44 & 115.16 & 10.62 & 87.68 \\
\hline & 20 & 12.41 & 116.16 & 13.41 & 87.29 \\
\hline \multirow[t]{3}{*}{19} & 300 & 4.83 & 115.96 & 13.09 & 91.69 \\
\hline & 150 & 7.15 & 106.77 & 9.09 & 115.94 \\
\hline & 10 & 6.41 & 80.33 & 11.85 & 89.01 \\
\hline
\end{tabular}

The results in Fig. 3 show that all the 19 compounds could be rapidly absorbed by the gastrointestinal tract after the extract of FKQJF were orally administered to rats at a single dose of $3.2 \mathrm{~g} / \mathrm{kg}$ body weight, the concentration of which in plasma could be determined about $10 \mathrm{~min}$ later, and the plasma drug concentrations of most compounds reached the peak values at about 1-2 h. Two compounds, berberine (13) and andrograpanin (17), displayed peak times longer than $3 \mathrm{~h}$ (the $\mathrm{T}_{\max }$ were $8.00 \pm 0.00$ and $3.33 \pm 2.31$, respectively), indicating the gastrointestinal absorption of these two compounds was lower than that of other ones. The plasma concentrations of other compounds, 5-hydroxypicolinic acid methyl ester (2), acortatarin A (3), 9-epi-acortatarin A (4), jatrorrhizine (9), palmatine (11), naringenin (14) and 7-O-methylwogonin (19) decreased rapidly with the time prolongation after reaching peak values but could still be determined in plasma after a period. This result could be inferred that the absorption of this kind of compounds has the characteristics of fast absorption, fast elimination and long residence time. $\mathrm{C}_{\max }$ and $\mathrm{AUC}$ of 5-hydroxypicolinic acid methyl ester (2), salicylic acid (8), jatrorrhizine (9), palmatine (11) and berberine (13) were higher than the other compounds. However, in our previous study the oral absorption $\left(\mathrm{C}_{\max }\right)$ of alkaloids (jatrorrhizine, palmatine and berberine) was relatively low, possibly due to complex drug interaction in a Chinese medicine formula [18]. By comparing the pharmacokinetic characteristics of acortatarin A (3) and 9-epi-acortatarin $A(4)$, although the half-life of both was close $\left(t_{1 / 2}\right.$ was 2.66 and $2.20 \mathrm{~h}$ respectively), the AUC and $C_{\max }$ of acortatarin A were much higher than 9-epi-acortatarin A which indicated the bioavailability of 9-epiacortatarin A was lower than acortatarin A due to its relatively small exposure in the body. It can be seen that the structural characteristics of compounds itself influenced its absorption in vivo to a certain extent [19].

In addition, the concentration-time curves of 12 compounds including 3,4,5-trimethoxyphenol-1-O- $\beta$ D-glucopyranoside (1), neoandrographolide (5), transferulic acid (6), genistin (7), salicylic acid (8), ononin (10), andrographolide (12), berberine (13), 14-deoxy11,12-didehydroandrographolide (15), panicolin (16), andrograpanin (17), and $Z$-ligustilide (18) in this experiment showed double-peaks, which means that the plasma drug concentration reached the peak for the first time, and decreased with the time going but rose again to form the second peak. The bimodal phenomenon of these compounds may be related to the enterohepatic circulation [20-22], distribution [23], variable gastric emptying and double-site absorption [24, 25] during the absorption process of these compounds. As shown in Fig. 3 and Table 6, owing to the very similar structures, except for andrograpanin the other three diterpenes (neoandrographolide, andrographolide and 14-deoxy11,12-didehydroandrographolide) have similar pharmacokinetic parameters and concentration-time curves in vivo, being absorbed and eliminated with the similar rate. The first peak of the three diterpenes arises at 0-1 $\mathrm{h}$, and the second peak appears $1.5-3 \mathrm{~h}$ post dose. As showed in Fig. 1, neoandrographolide is the derivative of andrograpanin, in which the hydroxyl group is substituted by glucose, but their pharmacokinetic parameters are remarkably different, with $\mathrm{T}_{\max }$ at $1.00 \mathrm{~h}$, neoandrographolide was absorbed more rapidly than andrograpanin $\left(\mathrm{T}_{\max }\right.$ at $\left.3.33 \mathrm{~h}\right)$. Notably, distinct double-peaks of the four diterpenes were observed in plasma concentration-time curves of all these timosaponins, which was in conformity with the previous study [26]. However, the factors that may contribute to double peaks are not clear and the specific reasons need to be further studied. Double plasma concentration peaks were also observed 
Table 4 The stability of 19 compounds in FKQJF

\begin{tabular}{|c|c|c|c|c|c|c|c|}
\hline \multirow[t]{2}{*}{ Analyte } & \multirow[t]{2}{*}{ Spiked (ng/mL) } & \multicolumn{2}{|c|}{ Ordinary stability } & \multicolumn{2}{|c|}{ Freeze-thaw stability } & \multicolumn{2}{|c|}{ Long-term stability } \\
\hline & & Mean (\%) & RSD (\%) & Mean (\%) & RSD (\%) & Mean (\%) & RSD (\%) \\
\hline \multirow[t]{3}{*}{1} & 500 & 117.94 & 11.54 & 106.56 & 7.03 & 103.76 & 12.98 \\
\hline & 250 & 104.48 & 8.53 & 99.57 & 5.60 & 89.00 & 6.73 \\
\hline & 50 & 80.92 & 10.50 & 112.34 & 7.15 & 86.86 & 11.68 \\
\hline \multirow[t]{3}{*}{2} & 500 & 95.34 & 14.84 & 86.48 & 6.00 & 112.17 & 7.31 \\
\hline & 250 & 86.35 & 8.62 & 99.07 & 5.02 & 83.50 & 14.58 \\
\hline & 50 & 106.33 & 9.23 & 98.92 & 4.81 & 87.08 & 8.91 \\
\hline \multirow[t]{3}{*}{3} & 500 & 109.98 & 11.54 & 90.89 & 7.53 & 93.19 & 6.90 \\
\hline & 250 & 84.19 & 8.09 & 92.61 & 13.98 & 86.77 & 9.78 \\
\hline & 50 & 93.52 & 12.39 & 84.84 & 6.45 & 81.68 & 14.16 \\
\hline \multirow[t]{3}{*}{4} & 500 & 84.20 & 5.31 & 102.81 & 7.52 & 104.85 & 7.34 \\
\hline & 250 & 116.00 & 5.04 & 107.25 & 7.93 & 81.20 & 9.27 \\
\hline & 50 & 108.94 & 8.11 & 91.90 & 5.35 & 118.34 & 5.70 \\
\hline \multirow[t]{3}{*}{5} & 600 & 94.88 & 10.89 & 113.31 & 8.05 & 82.61 & 8.14 \\
\hline & 300 & 103.80 & 5.21 & 80.22 & 4.40 & 97.44 & 9.91 \\
\hline & 60 & 81.32 & 11.81 & 109.12 & 7.42 & 113.28 & 4.21 \\
\hline \multirow[t]{3}{*}{6} & 600 & 91.44 & 14.45 & 88.33 & 12.69 & 102.00 & 14.51 \\
\hline & 300 & 109.93 & 12.98 & 102.20 & 12.84 & 91.27 & 7.41 \\
\hline & 60 & 88.22 & 8.15 & 115.63 & 7.36 & 83.07 & 6.13 \\
\hline \multirow[t]{3}{*}{7} & 500 & 109.98 & 11.54 & 90.89 & 7.53 & 97.81 & 11.96 \\
\hline & 250 & 84.19 & 8.09 & 92.61 & 13.98 & 104.72 & 5.20 \\
\hline & 50 & 93.52 & 12.39 & 84.84 & 6.45 & 118.09 & 13.14 \\
\hline \multirow[t]{3}{*}{8} & 500 & 103.60 & 11.87 & 88.21 & 10.59 & 87.97 & 7.21 \\
\hline & 250 & 108.42 & 9.44 & 102.50 & 8.24 & 114.13 & 11.46 \\
\hline & 50 & 95.42 & 14.51 & 80.11 & 11.62 & 109.80 & 5.76 \\
\hline \multirow[t]{3}{*}{9} & 150 & 92.51 & 13.34 & 113.07 & 8.98 & 98.06 & 13.75 \\
\hline & 75 & 93.01 & 6.11 & 93.19 & 6.90 & 91.97 & 4.96 \\
\hline & 25 & 104.79 & 12.65 & 86.77 & 9.78 & 80.63 & 9.89 \\
\hline \multirow[t]{3}{*}{10} & 500 & 103.90 & 7.69 & 81.68 & 14.16 & 107.95 & 7.12 \\
\hline & 250 & 82.57 & 11.25 & 102.95 & 7.36 & 81.88 & 12.37 \\
\hline & 50 & 95.59 & 9.28 & 118.81 & 13.10 & 95.03 & 9.95 \\
\hline \multirow[t]{3}{*}{11} & 200 & 112.88 & 4.17 & 86.16 & 10.51 & 89.65 & 10.46 \\
\hline & 100 & 81.64 & 9.85 & 98.74 & 14.77 & 101.38 & 11.50 \\
\hline & 5 & 92.36 & 14.37 & 94.51 & 12.37 & 87.02 & 7.26 \\
\hline \multirow[t]{3}{*}{12} & 600 & 85.93 & 4.56 & 93.19 & 4.61 & 96.64 & 14.09 \\
\hline & 300 & 107.50 & 8.26 & 86.83 & 6.24 & 94.37 & 7.35 \\
\hline & 60 & 115.56 & 13.37 & 84.52 & 8.98 & 115.89 & 10.17 \\
\hline \multirow[t]{3}{*}{13} & 200 & 113.97 & 5.23 & 104.87 & 6.41 & 114.48 & 6.54 \\
\hline & 100 & 103.56 & 9.41 & 110.44 & 4.41 & 81.78 & 7.88 \\
\hline & 5 & 84.57 & 12.21 & 97.72 & 11.87 & 102.75 & 5.51 \\
\hline \multirow[t]{3}{*}{14} & 500 & 101.11 & 11.28 & 84.71 & 9.66 & 99.51 & 14.31 \\
\hline & 250 & 92.68 & 8.37 & 116.86 & 10.11 & 103.10 & 5.36 \\
\hline & 50 & 80.39 & 14.63 & 88.34 & 7.21 & 91.66 & 12.00 \\
\hline \multirow[t]{3}{*}{15} & 600 & 82.90 & 5.58 & 118.41 & 13.88 & 88.35 & 11.17 \\
\hline & 300 & 119.43 & 8.54 & 105.94 & 5.17 & 98.43 & 11.78 \\
\hline & 60 & 89.92 & 7.89 & 114.11 & 5.74 & 100.55 & 9.41 \\
\hline 16 & 500 & 88.55 & 10.19 & 95.34 & 14.39 & 95.48 & 14.48 \\
\hline & 250 & 92.98 & 9.71 & 108.03 & 7.63 & 89.82 & 11.06 \\
\hline & 50 & 83.35 & 10.11 & 105.76 & 13.36 & 105.80 & 14.99 \\
\hline
\end{tabular}


Table 4 (continued)

\begin{tabular}{|c|c|c|c|c|c|c|c|}
\hline \multirow[t]{2}{*}{ Analyte } & \multirow[t]{2}{*}{ Spiked (ng/mL) } & \multicolumn{2}{|c|}{ Ordinary stability } & \multicolumn{2}{|c|}{ Freeze-thaw stability } & \multicolumn{2}{|c|}{ Long-term stability } \\
\hline & & Mean (\%) & RSD (\%) & Mean (\%) & RSD (\%) & Mean (\%) & RSD (\%) \\
\hline \multirow[t]{3}{*}{17} & 600 & 89.06 & 13.56 & 115.83 & 10.90 & 117.51 & 8.16 \\
\hline & 300 & 117.99 & 8.45 & 86.68 & 7.22 & 90.66 & 13.65 \\
\hline & 60 & 81.80 & 13.15 & 82.73 & 12.65 & 87.43 & 14.67 \\
\hline \multirow[t]{3}{*}{18} & 400 & 106.31 & 5.16 & 104.63 & 14.09 & 118.76 & 7.32 \\
\hline & 200 & 86.65 & 11.80 & 112.10 & 12.30 & 86.82 & 11.71 \\
\hline & 20 & 107.46 & 10.78 & 88.16 & 4.78 & 114.56 & 10.35 \\
\hline \multirow[t]{3}{*}{19} & 300 & 96.04 & 14.20 & 94.97 & 5.56 & 85.96 & 7.14 \\
\hline & 150 & 80.66 & 4.23 & 111.86 & 11.51 & 84.29 & 11.25 \\
\hline & 10 & 96.33 & 12.53 & 103.66 & 13.37 & 116.14 & 5.09 \\
\hline
\end{tabular}

in the plasma concentration curves profiles of berberine, which was consistent with results from previous studies [27]. Distribution re-absorption and enterohepatic circulation may contribute to double peaks phenomenon. It was reported that while the berberine was absorbed, it was distributed rapidly with higher concentration in tissues than that of the plasma, which is possible for the drug to transfer from tissues to plasma and causes another peak in plasma [28]. Another possible cause of bimodal phenomena is that berberine inhibited gastrointestinal peristalsis which influenced drug absorption [29]. Moreover, one glucoside (3,4,5-trimethoxyphenol-1-O$\beta$-D-glucopyranoside) [18], a flavone (genistin) [30] and a phthalide (Z-ligustilide) [31] presented a double-peak absorption phase, which were reported. It is well known that the absorption of compounds in TCM is a very complex process that manifests itself through potential interaction with a host of physicochemical and physiological variables. Therefore, further detailed absorption studies are needed to elucidate the mechanism of the doublepeak phenomenon in pharmacokinetics.

\section{Discussion}

In our previous study, we systematically studied the chemical constituents of FKQJF as well as the single herbs, Mahoniae Caulis and Spatholobi Caulis [14, 15]. We also established a high-performance liquid chromatography method for fingerprint and simultaneous quantification of eight major compounds in Fukeqianjin capsule [32]. Moreover, our group has already studied the PK behaviors of Mahoniae Caulis and Spatholobi Caulis, which is a significant foundation to investigate the PK study of the formula more effectively [18, 33]. On the basis of compound chemical components research of
FKQJF and its vital components, we studied the major effective compounds observed in blood through the pharmacokinetics research, which are the mostly possible material basis of FKQJF. These studies will provide helpful information for clarifying bioactive constituents and action mechanism of this TCM prescription.

\section{Conclusions}

With the rapid development of analytical techniques, LC-MS is increasingly used in the analysis of complex TCM systems [33, 34]. UFLC-MS/MS technology combines the advantages of the rapid separation of liquid chromatography, accurate molecular weight measurement of mass spectrometry along with fragmented ion information to pinpoint and analyze the $\mathrm{ng} / \mathrm{mL}$ range of compounds accurately. It provided an accurate and reliable analytical method for the determination of various compounds in TCM and their pharmacokinetics of absorption, distribution, metabolism and excretion in vivo [35-37]. In this study, a rapid, efficient and sensitive method for detecting the absorption behavior of the compounds in Fukeqianjin formula was established based on the characteristics of its components. The PK behaviors of 19 compounds absorbed into the blood, including 4 diterpenoids, 6 alkaloids, 5 flavones, 1 lactone and 3 organic acids, were determined using this method, and the key kinetic parameters, such as $\mathrm{T}_{\max }$, half-life, AUC and MRT were obtained. The result of this experiment could help further research on promotion of the pharmacological activity and dosage form design of FKQJF, as well as potential clinical application of its active compounds, and provides a key link between the complex chemical system of FKQJF and its in vivo activities. 
Table 5 The recovery and matrix effect of 19 compounds in FKQJF

\begin{tabular}{|c|c|c|c|c|c|}
\hline \multirow[t]{2}{*}{ Analyte } & \multirow[t]{2}{*}{ Spiked (ng/mL) } & \multicolumn{2}{|c|}{ Recovery } & \multicolumn{2}{|c|}{ Matrix effect } \\
\hline & & Mean & RSD \% & Mean & RSD \% \\
\hline \multirow[t]{3}{*}{1} & 500 & 91.34 & 8.16 & 83.40 & 4.46 \\
\hline & 250 & 117.65 & 10.34 & 86.26 & 13.09 \\
\hline & 50 & 95.57 & 9.65 & 95.83 & 12.51 \\
\hline \multirow[t]{3}{*}{2} & 500 & 82.25 & 6.95 & 95.64 & 14.43 \\
\hline & 250 & 88.18 & 5.16 & 118.82 & 9.91 \\
\hline & 50 & 95.72 & 13.70 & 83.95 & 13.26 \\
\hline \multirow[t]{3}{*}{3} & 500 & 112.88 & 4.17 & 86.16 & 10.51 \\
\hline & 250 & 81.64 & 9.85 & 98.74 & 14.77 \\
\hline & 50 & 92.36 & 14.37 & 94.51 & 12.37 \\
\hline \multirow[t]{3}{*}{4} & 500 & 96.00 & 10.04 & 109.41 & 10.74 \\
\hline & 250 & 112.34 & 5.75 & 96.07 & 7.33 \\
\hline & 50 & 93.48 & 12.31 & 81.89 & 7.77 \\
\hline \multirow[t]{3}{*}{5} & 600 & 116.92 & 7.90 & 99.37 & 11.80 \\
\hline & 300 & 93.25 & 7.38 & 81.76 & 7.84 \\
\hline & 60 & 113.16 & 11.01 & 90.40 & 14.03 \\
\hline \multirow[t]{3}{*}{6} & 600 & 116.07 & 14.09 & 95.91 & 5.33 \\
\hline & 300 & 90.96 & 9.27 & 101.58 & 7.86 \\
\hline & 60 & 113.50 & 10.86 & 83.42 & 4.92 \\
\hline \multirow[t]{3}{*}{7} & 500 & 94.80 & 10.92 & 83.83 & 4.18 \\
\hline & 250 & 84.24 & 13.75 & 80.63 & 11.34 \\
\hline & 50 & 86.90 & 14.70 & 105.95 & 14.40 \\
\hline \multirow[t]{3}{*}{8} & 500 & 114.26 & 10.58 & 106.24 & 11.57 \\
\hline & 250 & 97.53 & 7.22 & 91.89 & 8.13 \\
\hline & 50 & 82.58 & 8.09 & 100.86 & 4.65 \\
\hline \multirow[t]{3}{*}{9} & 150 & 88.02 & 5.08 & 115.13 & 5.53 \\
\hline & 75 & 84.66 & 4.90 & 114.37 & 9.09 \\
\hline & 25 & 97.35 & 5.71 & 96.57 & 11.85 \\
\hline \multirow[t]{3}{*}{10} & 500 & 114.19 & 12.24 & 112.83 & 4.96 \\
\hline & 250 & 119.00 & 13.92 & 116.16 & 13.93 \\
\hline & 50 & 93.86 & 11.51 & 88.16 & 4.67 \\
\hline \multirow[t]{3}{*}{11} & 200 & 103.16 & 5.57 & 88.83 & 6.67 \\
\hline & 100 & 100.81 & 5.27 & 102.26 & 6.90 \\
\hline & 10 & 90.40 & 12.70 & 80.62 & 11.88 \\
\hline \multirow[t]{3}{*}{12} & 600 & 113.68 & 8.76 & 114.11 & 8.79 \\
\hline & 300 & 94.96 & 14.89 & 85.75 & 7.80 \\
\hline & 60 & 111.70 & 4.41 & 119.18 & 11.76 \\
\hline \multirow[t]{3}{*}{13} & 200 & 94.08 & 14.89 & 119.79 & 12.86 \\
\hline & 100 & 114.75 & 9.32 & 80.43 & 4.68 \\
\hline & 10 & 85.57 & 11.82 & 85.26 & 6.47 \\
\hline \multirow[t]{3}{*}{14} & 500 & 119.18 & 6.16 & 83.89 & 6.95 \\
\hline & 250 & 112.28 & 7.14 & 84.01 & 9.14 \\
\hline & 50 & 119.90 & 10.03 & 114.12 & 7.35 \\
\hline \multirow[t]{3}{*}{15} & 600 & 82.03 & 6.08 & 91.20 & 8.50 \\
\hline & 300 & 80.71 & 5.05 & 106.55 & 11.58 \\
\hline & 60 & 82.33 & 7.78 & 96.12 & 12.48 \\
\hline
\end{tabular}

Table 5 (continued)

\begin{tabular}{|c|c|c|c|c|c|}
\hline \multirow{2}{*}{ Analyte } & \multirow[t]{2}{*}{ Spiked (ng/mL) } & \multicolumn{2}{|c|}{ Recovery } & \multicolumn{2}{|c|}{ Matrix effect } \\
\hline & & Mean & RSD \% & Mean & RSD \% \\
\hline \multirow[t]{3}{*}{16} & 500 & 82.87 & 9.34 & 113.66 & 4.04 \\
\hline & 250 & 96.22 & 9.00 & 100.13 & 14.14 \\
\hline & 50 & 101.27 & 11.48 & 88.82 & 14.28 \\
\hline \multirow[t]{3}{*}{17} & 600 & 91.18 & 11.92 & 89.61 & 9.44 \\
\hline & 300 & 90.15 & 10.63 & 99.43 & 10.45 \\
\hline & 60 & 101.00 & 10.52 & 86.38 & 9.42 \\
\hline \multirow[t]{3}{*}{18} & 400 & 110.60 & 6.17 & 83.36 & 9.40 \\
\hline & 200 & 96.94 & 9.84 & 98.95 & 9.81 \\
\hline & 20 & 99.16 & 9.57 & 96.26 & 12.07 \\
\hline \multirow[t]{3}{*}{19} & 300 & 88.37 & 8.76 & 83.94 & 8.74 \\
\hline & 150 & 95.79 & 5.85 & 86.30 & 11.95 \\
\hline & 10 & 103.73 & 7.60 & 102.13 & 4.23 \\
\hline
\end{tabular}



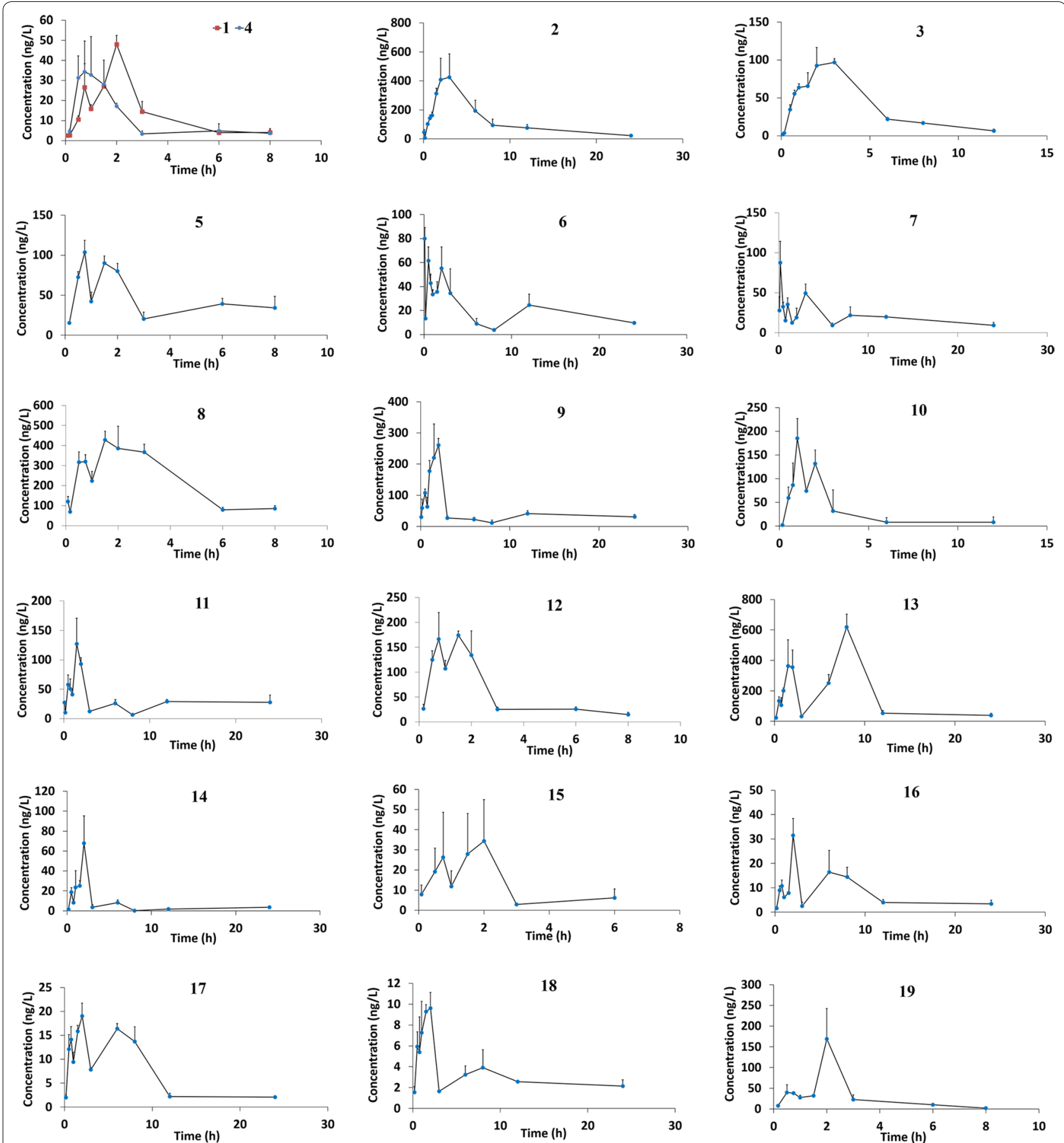

Fig. 3 The plasma concentration-time curves of 19 FKQJF compounds 
Table 6 The main pharmacokinetic parameters of 19 FKQJF compounds in plasma of rats

\begin{tabular}{|c|c|c|c|c|c|c|c|}
\hline Analyte & $A U C_{0 \rightarrow t}(\mathrm{ng} \mathrm{h} / \mathrm{mL})$ & $A U C_{0 \rightarrow \infty}(\mathrm{ng} \mathrm{h} / \mathrm{mL})$ & $\mathrm{MRT}_{0 \rightarrow \mathrm{t}}(\mathrm{h})$ & $\mathrm{MRT}_{0 \rightarrow \infty}(\mathrm{h})$ & $t_{1 / 2}(h)$ & $\mathrm{T}_{\max }(\mathrm{h})$ & $C_{\max }(n g / m L)$ \\
\hline 1 & $108.74 \pm 11.40$ & $115.09 \pm 15.76$ & $2.60 \pm 0.12$ & $3.37 \pm 0.26$ & $1.79 \pm 0.44$ & $2.00 \pm 0.00$ & $47.99 \pm 4.41$ \\
\hline 2 & $2967.61 \pm 169.49$ & $3110.48 \pm 38.66$ & $6.51 \pm 0.66$ & $8.09 \pm 1.32$ & $5.27 \pm 2.94$ & $2.17 \pm 0.76$ & $477.02 \pm 33.31$ \\
\hline 3 & $463.00 \pm 29.50$ & $489.12 \pm 37.60$ & $3.67 \pm 0.14$ & $4.32 \pm 0.47$ & $2.66 \pm 0.69$ & $2.33 \pm 0.58$ & $101.53 \pm 18.42$ \\
\hline 4 & $80.47 \pm 9.64$ & $92.61 \pm 21.43$ & $2.38 \pm 0.24$ & $3.25 \pm 0.41$ & $2.20 \pm 1.24$ & $1.00 \pm 0.50$ & $46.84 \pm 6.78$ \\
\hline 5 & $344.22 \pm 43.08$ & $504.72 \pm 108.63$ & $3.51 \pm 0.24$ & $7.55 \pm 1.93$ & $3.89 \pm 0.85$ & $1.00 \pm 0.43$ & $103.90 \pm 14.93$ \\
\hline 6 & $466.39 \pm 51.94$ & $1012.04 \pm 558.43$ & $9.19 \pm 1.00$ & $13.95 \pm 9.49$ & $10.49 \pm 6.63$ & $0.08 \pm 0.00$ & $79.85 \pm 9.43$ \\
\hline 7 & $468.14 \pm 48.36$ & $550.30 \pm 70.65$ & $9.04 \pm 0.68$ & $14.25 \pm 3.28$ & $7.68 \pm 3.01$ & $0.17 \pm 0.00$ & $87.65 \pm 26.65$ \\
\hline 8 & $1800.70 \pm 154.66$ & $2142.54 \pm 167.73$ & $2.88 \pm 0.15$ & $4.31 \pm 0.67$ & $2.70 \pm 0.54$ & $1.67 \pm 0.29$ & $432.72 \pm 53.10$ \\
\hline 9 & $1090.97 \pm 109.82$ & $2548.08 \pm 277.22$ & $8.96 \pm 0.40$ & $10.52 \pm 4.72$ & $9.65 \pm 4.91$ & $1.83 \pm 0.29$ & $269.68 \pm 24.01$ \\
\hline 10 & $369.68 \pm 155.83$ & $374.65 \pm 153.08$ & $2.54 \pm 1.12$ & $3.13 \pm 1.66$ & $1.64 \pm 0.52$ & $1.33 \pm 0.58$ & $192.33 \pm 31.98$ \\
\hline 11 & $691.13 \pm 93.26$ & $1638.89 \pm 155.01$ & $11.02 \pm 0.99$ & $14.16 \pm 8.89$ & $9.16 \pm 2.09$ & $1.67 \pm 0.29$ & $133.90 \pm 31.78$ \\
\hline 12 & $441.56 \pm 59.51$ & $480.47 \pm 71.86$ & $2.45 \pm 0.19$ & $3.10 \pm 0.33$ & $1.79 \pm 0.20$ & $1.00 \pm 0.43$ & $186.20 \pm 19.02$ \\
\hline 13 & $3803.21 \pm 170.75$ & $5627.52 \pm 2430.69$ & $8.04 \pm 0.88$ & $39.04 \pm 46.48$ & $38.76 \pm 53.16$ & $8.00 \pm 0.00$ & $619.12 \pm 84.57$ \\
\hline 14 & $143.85 \pm 16.54$ & $205.76 \pm 58.66$ & $6.67 \pm 1.42$ & $17.02 \pm 8.17$ & $12.11 \pm 9.32$ & $2.00 \pm 0.00$ & $67.74 \pm 27.55$ \\
\hline 15 & $74.29 \pm 17.48$ & $81.11 \pm 19.35$ & $2.21 \pm 0.48$ & $3.05 \pm 1.01$ & $1.20 \pm 0.74$ & $1.42 \pm 0.63$ & $47.74 \pm 5.92$ \\
\hline 16 & $177.10 \pm 17.10$ & $250.82 \pm 97.56$ & $8.68 \pm 1.17$ & $20.144 \pm 5.01$ & $12.64 \pm 12.72$ & $2.00 \pm 0.00$ & $31.45 \pm 6.94$ \\
\hline 17 & $160.80 \pm 12.69$ & $178.64 \pm 14.30$ & $7.30 \pm 0.38$ & $9.82 \pm 0.45$ & $5.98 \pm 0.40$ & $3.33 \pm 2.31$ & $19.20 \pm 2.48$ \\
\hline 18 & $74.65 \pm 8.31$ & $193.63 \pm 27.92$ & $9.85 \pm 0.85$ & $48.18 \pm 39.82$ & $33.59 \pm 27.13$ & $1.83 \pm 0.29$ & $10.19 \pm 0.58$ \\
\hline 19 & $248.66 \pm 65.48$ & $251.96 \pm 62.45$ & $2.44 \pm 0.12$ & $2.55 \pm 0.21$ & $1.10 \pm 0.47$ & $2.00 \pm 0.00$ & $169.08 \pm 73.48$ \\
\hline
\end{tabular}

\section{Abbreviations}

UFLC-MS/MS: Ultra-fast liquid chromatography coupled with triple quadrupole tandem mass spectrometry; FKQJF: Fukeqianjin formula; TCM: Traditional Chinese medicine; I.S.: Internal standard; MRM: Multiple reaction-monitoring; LLOD: Lower limit of detection; LLOQ: Lower limit of quantitation; RSD: Relative standard deviation; QC: Quality control; PK: Pharmacokinetic; MeOH: Methanol; CAN: Acetonitrile; SD: Sprague-Dawley; ESI: Electrospray ionization source.

\section{Acknowledgements}

The authors wish to express their gratitude to all staffs, especially all the teachers in the State Key Laboratory of Natural and Biomimetic Drugs, Department of Natural Medicines, School of Pharmaceutical Sciences, Peking University Health Science Center, Peking University.

\section{Authors' contributions}

$X W Y$ and $P Z$ designed the experiments; KHW, YFY and LL were responsible for the data analysis; KHW, XYL, LZ and WX were responsible for the previous research;YTZ, KFP, YG and NFL fund the research; KHW wrote the original draft, $Y T Z$ and $X W Y$ review and editing the manuscript. $L L$ and $X W Y$ revised the manuscript. All authors read and approved the final manuscript.

\section{Funding}

This research was supported by the National Chinese Medicine Standardization Project (2YB2H-C-HUN-21)

\section{Availability of data and materials}

All data included in this article are available from the corresponding author upon request.

\section{Ethics approval and consent to participate}

The animal study was performed according to the guideline of the Care and Use of Laboratory Animals in Beijing that was approved by Animal Care and Use Committee of Peking University (Approval No. LA 2018143, 1 March 2018).

\section{Consent for publication}

All authors have provided consent for publication in the journal of Chinese Medicine.

\section{Conflicts of interests}

The authors declare no conflict of interest.

\section{Author details}

${ }^{1}$ State Key Laboratory of Natural and Biomimetic Drugs, Department of Natural Medicines, School of Pharmaceutical Sciences, Peking University Health Science Center, Peking University, No. 38, Xueyuan Road, Haidian District, Beijing 100191, China. ${ }^{2}$ Zhuzhou Qianjin Pharmaceutical Co., Ltd, Zhuzhou 412000, China.

Received: 3 February 2020 Accepted: 18 June 2020

Published online: 25 July 2020

\section{References}

1. Chinese Pharmacopoeia Commission. Pharmacopoeia of the People's Republic of China, vol. I. Beijing: China Medical Science and Technology Press; 2015. p. 902-3 (In Chinese)

2. Li W, Zou L, Gong Y, Zhang P, Wang P, Zhang Y, et al. Effect of Fuke Qianjin tablets on pharmacokinetics of Azithromycin in rats with chronic pelvic inflammatory disease. China J Chin Mater Med. 2016;41(12):2339-43 (In Chinese).

3. Shi ZY, Guo JS, Yuan JL, Zuo ZW, Yue ZH. Influence of Fuke Qianjin tablets on blood cells and histopathological manifestations of acute pelvic inflammation in rats. Chin J Exp Tradit Med Form. 2011;17(12):199-202 (In Chinese)

4. Wang L, Xu R, Zhang SH, Ma SY, Xue YN. Meta-analysis on efficacy of Fuke Qianjin tablets (capsules) combined with antibiotics in treatment of endometritis. China J Chin Mater Med. 2016:41(16):3090-5 (In Chinese).

5. Zhang Y, Li W, Zou L, Gong Y, Zhang P, Xing SS, et al. Metabonomic study of the protective effect of Fukeqianjin formula on multi-pathogen induced pelvic inflammatory disease in rats. Chin Med. 2018;13(1):61.

6. Lu YB, Qu JY, Guo JS, Zuo ZW, Shi ZY, Wang XJ, et al. Effect of Fuke Qianjin tablet on TNF- $a$ and IL-2 mRNA transcription in the uteri and ovary tissues of acute pelvic inflammatory disease in rats. Chin Tradit Pat Med. 2012;34(1):29-33 (In Chinese). 
7. Wang KH, Zhang YT, Yang XW, Xu W, Zhang P, Gong Y, et al. Chemical constituents from Fukeqianjin formula. China J Chin Mater Med. 2018:43(11):2300-12 (In Chinese).

8. Liu J, Wang ZT, Ji LL. In vivo and in vitro anti-inflammatory activities of neoandrographolide. Am J Chin Med. 2007;35(2):317-28.

9. Liu J, Wang ZT, Ge BX. Andrograpanin, isolated from Andrographis paniculata, exhibits anti-inflammatory property in lipopolysaccharide-induced macrophage cells through down-regulating the p38 MAPKs signaling pathways. Int Immunopharmacol. 2008;8(7):951-8.

10. Liu X, Hu Z, Shi Q, Zeng H, Shen Y, Jin H, et al. Anti-inflammatory and anti-nociceptive activities of compounds from Tinospora sagittata (Oliv.) Gagnep. Arch Pharmacal Res. 2010;33(7):981-7.

11. Esra K, Müberra K, Erdem Y, Hüsnü CB. A comparative study on the anti-inflammatory, antinociceptive and antipyretic effects of isoquinoline alkaloids from the roots of Turkish Berberis species. Life Sci. 2002;72(6):645-57.

12. Cornwell T, CohickW, Raskin I. Dietary phytoestrogens and health. Phytochemistry. 2004;65(8):995-1016.

13. Dakora FD, Phillips DA. Diverse functions of isoflavonoids in legumes transcend anti-microbial definitions of phytoalexins. Physiol Mol Plant Pathol. 1996;49(1):1-20.

14. Cui ZX, Xu W, Yang XW, Li FJ, Gong Y, Liu NF, et al. Chemical constituents of lipophilic parts in water extrct from stem of Mahonia fortunei Chin Tradit Herb Drugs. 2018;49(1):80-9 (In Chinese).

15. Liu XY, Xu W, Zhang P, et al. Isolation and identification of flavonoids from Spatholobi Caulis. China J Chin Mater Med. 2020;45(6):1384-92 (In Chinese)

16. Xu QX, Hu Y, Li GY, Xu W, Zhang YT, Yang XW. Multi-target anti-Alzheimer activities of four prenylated compounds from Psoralea Fructus. Molecules. 2018;23(3):614.

17. Bioanalytical Method Validation Guidance for Industry. Silver Spring: Food and Drug Administration; 2018. pp. 4-10. https://www.fda.gov/ media/70858/download. Accessed 2nd Aug 2018.

18. Liu L, Cui ZX, Yang XW, et al. Simultaneous characterisation of multiple Mahonia fortunei bioactive compounds in rat plasma by UPLC-MS/ MS for application in pharmacokinetic studies and anti-inflammatory activity in vitro. J Pharm Biomed Anal. 2019. https://doi.org/10.1016/j. jpba.2019.113013.

19. Han YJ, Kang B, Yang E-J, Choi M-K, Song I-S. Simultaneous determination and pharmacokinetic characterization of glycyrrhizin, isoliquiritigenin, liquiritigenin, and liquiritin in rat plasma following oral administration of glycyrrhizae radix extract. Molecules. 1816;2019:24. https://doi.org/10.3390/molecules24091816.

20. Kung TA, Lee $\mathrm{SH}$, Wang WH. Determination of sulfamonomethoxine in tilapia (Oreochromis niloticus $\times$ Oreochromis mossambicus) by liquid chromatography-tandem mass spectrometry and its application pharmacokinetics study. J Food Drug Anal. 2019;27(1):339-46.

21. Chen F, Li L, Xu F, Sun Y, Du FF, Ma XT, et al. Systemic and cerebral exposure to and pharmacokinetics of flavonols and terpene lactones after dosing standardized Ginkgo biloba leaf extracts to rats via different routes of administration. Br J Pharmacol. 2013;170(2):440-57.

22. Zuo F, Nakamura N, Akao T, Hattori M. Pharmacokinetics of berberine and its main metabolites in conventional and pseudo germ-free rats determined by liquid chromatography/ion trap mass spectrometry. Drug Metab Dispos. 2006;34(12):2064-72.

23. Piyapolrungroj N, Zhou YS, Li C, et al. Cimetidine absorption and elimination in rat small intestine. Drug Metab Dispos. 2000;28:65-72.

24. Metsugi Y, Miyaji Y, Ogawara K, Higaki K, Kimura T. Appearance of double peaks in plasma concentration-time profile after oral administration depends on emptying profile and weight function. Pharm Res. 2008;25:886-95.

25. Lu T, Song J, Huang F, et al. Comparative pharmacokinetics of baicalin after oral administration of pure baicalin, Radix scutellariae extract and Huang-Lian-Jie-Du-Tang to rats. J Ethnopharmacol. 2007;110(3):412-8.

26. Wang J, Yang WQ, Wang GL, et al. Determination of six components of Andrographis paniculata extract and one major metabolite of andrographolide in rat plasma by liquidchromatography-tandem mass spectrometry. J Chromatogr B. 2014;951-952:78-88.

27. Chang YX, Ge AH, Yu XA, et al. Simultaneous determination of four phenolic acids and seven alkaloids in rat plasma after oral administration of traditional Chinese medicinal preparation Jinqi Jiangtang Tablet by LC-ESI-MS/MS. J Pharm Biomed Anal. 2016;117:1-10.

28. Deng Y, Liao Q, Li S, et al. Simultaneous determination of berberine, palmatine and jatrorrhizine by liquid chromatography-tandem mass spectrometry in rat plasma and its application in a pharmacokinetic study after oral administration of coptis-evodia herb couple. J Chromatogr B. 2008:863(2):195-205.

29. Feng YJ, Li YY, Chen CQ, et al. Inhibiting roles of berberine in gut movement of rodents are related to activation of the endogenous opioid system. Phytother Res. 2013;27:1564-71.

30. Wang $X Y$, Jin $Z$, Ling $X$, et al. Pharmacokinetic characteristics of fourteen main components of Gegen Qinlian decoction in rats. China J Chin Mater Med. 2018;43(23):4724-33.

31. Yang $L$, Liu JL, Guo BR et al. Pharmacokinetics of ligustilide in rats after Ig administration of petroleum ether extract of Angelica sinensis(Oliv.) Diels. Nat Prod Res Dev. 2014; 26:1276-1280, 1326

32. Wang KH, Zhang YT, Yang XW, Xu W, Zhang P, Peng KF, et al. Characteristical fingerprint and multi-components quantitative determination for Fukeqianjin capsule by HPLC. China J Chin Mater Med. 2019;44(7):156472 (In Chinese).

33. Zhang L, Liu XY, Xu W, Yang XW. Pharmacokinetics comparison of 15 ginsenosides and 3 aglycones in Ginseng Radix et Rhizoma and Baoyuan decoction using ultra-fast liquid chromatography coupled with triple quadrupole tandem mass spectrometry. Phytomedicine. 2019;59:152775. https://doi.org/10.1016/j.phymed.2018.11.035.

34. Yang YF, Zhang YB, Chen ZJ, Zhang YT, Yang XW. Plasma pharmacokinetics and cerebral nuclei distribution of major constituents of Psoraleae fructus in rats after oral administration. Phytomedicine. 2018;38:166-74.

35. Wu XW, Zhang YB, Zhang L, Yang XW. Simultaneous quantification of 33 active components in Notopterygii Rhizoma et Radix using ultra high performance liquid chromatography with tandem mass spectrometry. J Chromatogr B. 2018;1092:244-51.

36. Liu CS, Jin Z, Chen FL, Tan XM. Tissue distribution of 14 bioactive components after oral administration of Gegen Qinlian Tang in rats. Chin J Exp Tradit Med Form. 2019;25(10):93-101 (In Chinese).

37. Liu LL, Li H, He D, Wang ML, Liu ZL, Shu YS, et al. Metabolic and excretory process of citri reticulatae pericarpium viride and citri reticulatae pericarpium in rats' urine and feces analyzed by RRLC-QqQ-MS ${ }^{n}$. China J Chin Mater Med. 2018;43(22):4519-27 (In Chinese)

\section{Publisher's Note}

Springer Nature remains neutral with regard to jurisdictional claims in published maps and institutional affiliations.

Ready to submit your research? Choose BMC and benefit from:

- fast, convenient online submission

- thorough peer review by experienced researchers in your field

- rapid publication on acceptance

- support for research data, including large and complex data types

- gold Open Access which fosters wider collaboration and increased citations

- maximum visibility for your research: over 100M website views per year

At BMC, research is always in progress.

Learn more biomedcentral.com/submissions 